\title{
VEGANISM 2.0: GASTROMANIA, NUTRITION, AND DIGITAL COMMUNICATION
}

\author{
Simona Stano \\ Marie Curie Fellow \\ University of Turin and New York University \\ simona.stano@unito.it
}

\begin{abstract}
The vegan population has risen significantly over the past decade, and is expected to continue increasing. Social media are believed to have played a major role in such a rise. According to a Google study (2018), veganism started to spread markedly in 2012, the same year that Instagram became popular, and has then grown in correlation with the expansion of the social network (with over 88 million \#vegan posts out of a billion monthly active users and more than 500 million people using the platform daily today). Since 2016 conversations around veganism have increased also on Twitter, reaching nearly 20 million Tweets in 2018 and registering a further growth of $70 \%$ in 2019 . Moreover, the number of Google searches for veganism has spiked from a popularity rating of just 17 out of 100 in 2008 to 88 in 2018. Functioning both as platforms for sharing and commenting on information and as effective channels for proselytizing, these and other social media have evidently extended the boundaries of the vegan movement, making
\end{abstract}


it become one of the biggest contemporary food trends. This paper aims at identifying and describing the main cultural transformations and forms of life promoted by "veganism 2.0", based on a semiotic approach particularly attentive to the analysis of the narrative level and the patemic dimension. To this purpose, the intersections between the so-called "gastromania" and other trends characterising contemporary foodspheres, such as "gastro-anomy" and the "ideology of nutritionism" are taken into account, paying particular attention to the gastronomic discourse in present-day digital mediascapes and the complex dynamics characterising them.

Keywords: veganism, gastromania, digital communication, social media, semiotics

\section{Introduction}

Veganism is not a novelty: plant-based diets have been adopted by different communities along history. They have also become a fundamental part of specific religious and socio-cultural systems (Leitzmann 2014). However, it was officially established as a movement only in recent times, and more specifically in 1944, following the request by several members of the Vegetarian Society to establish a section devoted to non-dairy vegetarianism $^{1}$ (Stepaniak 2000).

The movement remained on the fringe for various decades, until it became increasingly mainstream in the 2010s, especially in the latter half. Social media are believed to have played a major role in such a rise. According to a Google study (2018), veganism started to spread markedly in 2012, the same year that Instagram became popular, and has then grown in correlation with the expansion of the social network (with over 88 million \#vegan posts out of a billion monthly active users and more than 500 million people using the platform daily today). Since 2016 conversations around veganism have increased also on Twitter, reaching nearly 20 million Tweets in 2018 and registering a further growth of $70 \%$ in 2019. Furthermore, the number of Google searches for veganism has spiked from a popularity rating of just 17 out of 100 in 2008 to 88 in $2018^{2}$. Functioning both as platforms for sharing and commenting on information and as ef-

\footnotetext{
${ }^{1}$ While the vegetarian diet excludes meat and fish, veganism promotes the avoidance of any product derived from animals - in diet and for any purpose.

${ }^{2}$ The qualitative aspects related to this data are discussed in the following paragraphs. The emphasis is here put on quantitative dimension - regardless of language, geographical context, sociological and economic data of the involved users, etc. - in order to empha-
} 
fective channels for proselytizing, these and other social media have evidently extended the boundaries of the vegan movement, making it one of the biggest contemporary food trends. This paper draws on a semiotic approach to identify and describe the main cultural transformations and forms of life promoted by "veganism 2.0".

\section{Digital communication and the rise of veganism $\mathbf{2 . 0}$}

In its 2018 annual report, the market research firm Brandwatch declared veganism the year's most popular nutrition and diet topic on popular social media platforms such as Twitter, Reddit and Instagram, based on the number of influencers discussing on it and the amount of posts featuring the hashtag "\#vegan". In accordance with similar studies carried out by other agencies, it also highlighted the main characterisation of such an online success, pointing out its convergence with other trend topics such as health and fitness, animal welfare, etc. Adopting a macro perspective, these studies provide an interesting overview of online veganism, but do not describe in detail their functioning mechanisms and the effects of meaning arising from them.

In the aim to fill this gap, the following paragraphs will reconsider the main aspects they highlight through a semiotic approach, referring to specific examples when relevant. More specifically, we will devote particular attention to the narrative level and the patemic dimension, also highlighting the intersections between the so-called "gastromania" (Marrone 2014b) and other trends characterising contemporary foodspheres, such as "gastro-anomy" (Fischler 1979) and the "ideology of nutritionism" (Scrinis 2008). This will allow us to present some general reflections about the gastronomic discourse in present-day digital mediascapes and the complex dynamics characterising them.

\subsection{The role of social media influencers}

According to marketing research, social media influencers - i.e. independent third party endorsers shaping audience attitudes through blogs, tweets, and other digital media (Freberga, Grahamb, McGaugheyc \& Freberg 2011: 90) - have played a crucial role in the recent enlargement of the vegan community. While trust in company websites and the news has decreased, social media have in fact become a major source of information for the younger generations, with influencers becoming their main refer-

sise the online growth of the vegan movement. For a detailed discussion of the politics and demographics of veganism, see in particular Martinelli \& Berkmaniené 2018. 
ence points. As effectively showed by Judith Friedlander and Chris Riedy (2018), the new media context has increasingly questioned the agenda setting theory, and especially the ability it attributes to the media to influence the importance placed on topics by their audiences (as described in McCombs and Reynolds 2002). Scholars argue that, while traditional media struggle with communicating unappealing messages (such as the need to eat less meat), social media influencers, being perceived as credible, trustworthy, and personally engaged in change ${ }^{3}$, have more potential to effectively reach and involve their audiences.

This is particularly relevant in the case of veganism, and more generally, food-related issues. As illustrated by Gianfranco Marrone (2014b), food has invaded every dimension of our existence, blurring the borders between our gastronomic experiences and the several discourses we produce on them. The result is a real "gastromania", or a "gastronomic mania", a media-fuelled obsession for food disjointed from any ethical or political concern or depth. Numerous "foodies" crowd social networks, also including vegan-oriented channels and accounts, not driven by a real interest in specific food regimes or ethics, but rather as a result of an ephemeral curiosity, of a disinterested appeal for novelty and diversion. In this sense, the role of influencers in making social media users approach veganism is crucial. Their posts, and especially the visual or audiovisual materials they usually dedicate to animal welfare, environmental issues or health concerns, go beyond superficial and ephemeral curiosity, "pricking" the reader (in the sense effectively described by Barthes's idea of punctum ${ }^{4}$ ). Thus, they mark the passage from a state of adiaphoria - that is to say, the general condition of indifference characterising the disinterested look of online foodies, consisting in the absence of both dysphoric and euphoric passions - to a state of diaphoria - namely a complex synthesis of dysphoria and euphoria, originating passions such as disdain or indignation. Hence the constitution of the reader/user as a patemic Subject (i.e. his/her "predisposition" to take part in the passional process) is realised. This paves the way to the phase of disposition (i.e. a preparatory phase towards clearly recognised

\footnotetext{
${ }^{3}$ Kristian Bankov in his paper here interestingly compares the "influencers system" to the "brand mythology system" (Vincent 2002), highlighting the crucial role played by influencers' lifestyles in the conversion of virtual systems of passions and beliefs (i.e. their mission) into concrete examples to be followed by their followers. For a further discussion on influencers' engagement strategies and effects, see in particular Schouten, Janssen \& Verspaget (2019), Tafesse \& Wood (2020) and Bankov (2021 in press).

${ }^{4}$ In his analysis of photography, Roland Barthes (1981: 27) described the punctum precisely as "that accident which pricks me (but also bruises me, is poignant to me)".
} 
patemic states) and the deployment of the canonical passional schema as illustrated by Greimas and Fontanille (1991). Clearly, this does not necessarily imply a permanent and firm interest, but certainly goes beyond a transient and unfocused look, and may possibly allow the activation of the Receiver-Subject's wanting-to-do. Moreover, influencers play a crucial role in transferring the knowing-how-to-do and being-able-to-do presupposed by the vegan performance. Such can be seen in the Instagram account Vegan Hacks or the various individuals (e.g. chef Gaz Oakley, Niomi Smart, Marcus Butler, EarthAndy, Mia Zarlengo, Mark Bittman, just to mention some of the most influential) who share easy and attainable vegan recipes, thus operating as helpers in the narrative programmes of the subjects willing or trying to approach veganism.

\subsection{Not only healthy: vegan food $\mathbf{2 . 0}$}

Drawing on analysis of online conversations around "veganism" and "plant-based diet" in the United States and the United Kingdom in 2018, Linkfluence identified three main communities which seem to be driving the vegan movement on social media (Fig. 1):

- holistic wellbeing seekers, focused on self-care and wellness;

- fitness and lifestyle community, motivated by a search for health and fitness;

- ethical foodies, attentive to animal welfare and sustainability.

\begin{tabular}{|c|c|c|c|}
\hline & $\begin{array}{l}\text { HOLISTIC WELLBEING } \\
\text { SEEKERS }\end{array}$ & $\begin{array}{l}\text { FITNESS \& LIFESTYLE } \\
\text { COMMUNITY }\end{array}$ & $\begin{array}{l}\text { ETHICAL } \\
\text { FOODIES }\end{array}$ \\
\hline Volume of posts & $\begin{array}{c}\text { US: } 320 k \text { | UK: } 89 k \\
\gamma \in\end{array}$ & $\begin{array}{c}\text { US: } 239 \mathrm{k} \text { |s UK: } 83 \mathrm{k} \\
76 \mathrm{e}\end{array}$ & US: $125 \mathrm{k}$ | UK: $43 \mathrm{k}$ \\
\hline What drives them & $\begin{array}{l}\text { self-love, self-care, } \\
\text { wellness, } \\
\text { mindfulness, curiosity }\end{array}$ & $\begin{array}{l}\text { self-optimization, } \\
\text { weight loss, } \\
\text { health }\end{array}$ & $\begin{array}{l}\text { altruism, compassion } \\
\text { animal welfare, } \\
\text { sustainability }\end{array}$ \\
\hline Popular hashtags & $\begin{array}{c}\text { \#plantbased \#vegan } \\
\text { \#cleaneating \#organic } \\
\text { \#healthyfood \#wellness } \\
\text { \#yummy }\end{array}$ & $\begin{array}{l}\text { \#vegan \#healthy } \\
\text { \#fitfam \#motivation } \\
\text { \#healthychoices } \\
\text { \#weightloss \#plantpower } \\
\text { \#fitfood }\end{array}$ & $\begin{array}{l}\text { \#crueityfree \#nongmo } \\
\text { \#organic \#realfood } \\
\text { \#natural \#animalrights } \\
\text { \#natural \#sustainable }\end{array}$ \\
\hline
\end{tabular}

Fig. 1: Linkfluence's social data research into the rise of veganism and plant-based diet in 2018 (๑ Linkfluence).

Such a classification, also confirmed by similar research findings, reflects a main opposition. In certain cases, veganism has a "use value" (cf. Greimas \& Courtés 1979), since it allows the subject to realise a junction with a second order object, i.e. health or well-being (in a practical valorisation, in 
the terms adopted by Jean-Marie Floch 1990). In other cases, it rather has a "basic value", as the subject finds himself/herself by identifying with it (utopian valorisation), such as in the case of "ethical foodies". This also relates veganism to different modalisations. In the first case, it is associated with a prescription (having-to-do) or a prohibition (having-not-to-do), recalling a logic according to which what one does - i.e. eating vegan food - defines what one is - healthy people (i.e. a causal regime, cf. Ferraro 1998). In the second case, it concerns an existential possibility (being-able-to-be), based on a positional regime where what one is - an ethical eater (or "ethical foodie", in the research's terms) - determines what one does - adopting a vegan lifestyle. In this respect, it is particularly interesting to consider the description that VSOCIETY, a vegan social networking platform intended to connect the vegan community worldwide, provides of itself:

An 'all-in-one ecosystem' collating everything ethical into one dashboard for users to discover content that is relevant and interesting to their lifestyle choices, with products, activities and content being made available to every user (https://www.veganlifemag.com/ new-vegan-social-network-platform-launches/).

Although interesting, this model seems to neglect a fundamental aspect of veganism 2.0: its ludic-aesthetic valorisation. Not even the most fleeting of looks would miss the evident "food porn"5 characterisation of the copious images accompanying the posts of vegan recipes, the discussions on vegan culinary experiments, the descriptions of vegan meals, etc. The examples illustrated in Fig. 2 are emblematic in this sense. The camera moves closer and closer to food, in an attempt to remove the veil and satisfy the typical "haptic" (cf. Marrone 2015a), i.e. tactile, look of food pornography ${ }^{6}$.

\footnotetext{
${ }^{5}$ The idea of food pornography was introduced by Rosalind Coward who, in Female Desire (1984), related the process of aestheticization process of food that has made the visual appearance of plates acquire more importance than the acts of cooking and eating themselves to the feminist cause, putting it in close correlation with the subordination of the female figure. Extending to a more general context, this approach subsequently resulted into an excess of consideration of food and, in particular, of its aesthetic dimension (see Ashley et al. 2004). Based on such a conception, for instance, Erin Metz McDonnell described food porn as "a set of visual aesthetics and practices that emphasize the pleasurable, sensual dimensions of food" (2016: 264), including techniques such as zoom, framing, orientation, and depth of field.

${ }^{6}$ For a more detailed description of the voyeuristic and tactile mechanism underlying the food porn aesthetics, in opposition to the erotic characterisation of "intermittence" (cf. Barthes 1973), see Stano 2018.
} 
Moreover, as is usual in the food porn aesthetics, products are chosen and associated with each other to create appealing eidetic and chromatic combinations (generally enhanced by means of filters and editing techniques, such as brightness, colour and saturation, to appear more visually pleasing), with the level of expression capturing the observer's attention and concurring to the attenuation of the differences among different food categories, including vegan and non-vegan products (which is of particular interest, as we will discuss in what follows).
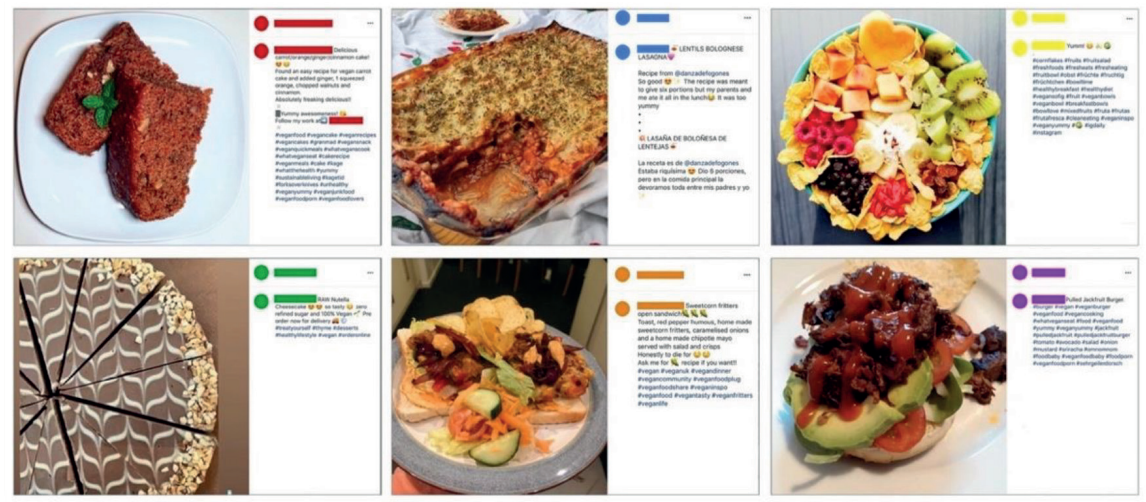

Fig. 2: Examples of visual posts concerning vegan food ${ }^{7}$.

Furthermore, the verbal text frequently includes references to the flavour of food and the pleasure deriving from it. This reinforces the denial of a simply utilitarian logic endorsing veganism as a way of attaining good health and well-being, rather promoting it as the expression of personal preferences and likings (in a regime that Ferraro would describe as perspective, since it reflects the Subject's individual view). This is particularly interesting, especially if referred to other trends characterising contemporary foodspheres, such as the so-called "ideology of nutritionism" (Scrinis 2008), which we will discuss in detail in the conclusion. Here it is essential to point out that, although taste is mainly overlooked in existing research (in the categories identified by Linkfluence, for instance, the hashtag "\#yummy" is reported for the holistic wellbeing seekers, but the emphasis is put on other factors, such as "self love, self-care, wellness, mindfulness, curiosity"), it is a crucial element for a correct understanding of the spread of veganism 2.0 , especially as related to the dynamics that will be discussed in the next paragraph.

\footnotetext{
7 The examples were selected for their relevance within a wide range of cases available on the web. Data has been minimised and anonymised in order to comply with ethics requirements.
} 


\subsection{Vegan, but not always}

We highlighted in the previous paragraph the importance of taste and the pleasure deriving from food in the representation of veganism in social media communication. Vegan food, traditionally dysphorized on the gastronomic level, being considered some sort of less tasty "option B" of animal-derived products, is now praised not only for being healthy and light, but also and especially for being "delicious", "yummy", "to die for" (cf. Fig. 2), etc. In this sense, as illustrated above, the aesthetics of so-called "food porn" have certainly played a crucial role, working as a unifying code of representation. Changes in the food production have also contributed to make vegan products more similar to non-vegan food, in terms of flavour, but also as regards form and appearance. Let us consider, for example, the Impossible ${ }^{\mathrm{TM}}$ Burger, the plant-based sausages and meatballs produced by Beyond Meat", and the other various examples of "faux meat products" which have become common on supermarket shelves, dining services menus, and especially social network platforms. Such products have progressively eroded the border between the "vegan" and "non-vegan" foodsphere (at least as far as the level of expression is concerned).

Hybridity has in fact evidently permeated veganism, which has increasingly accepted more casual and "flexitarian" forms within it. An emblematic case in this respect is Veganuary (https://veganuary.com), a UK non-profit organisation promoting veganism around the world by encouraging people to follow a vegan lifestyle for the month of January (and eventually beyond). Since its first event in 2014, participation has more than doubled each year, reaching 400.000 people $^{8}$ worldwide nowadays. Similar cases include everyday part-time veganism (such as the VB6 model introduced by Mark Bittman, consisting in sticking to the vegan diet before $6 \mathrm{pm}$ ), or fixed-day options (such as the famous Vegan Mondays). As we will discuss more in detail in the conclusion, such habits seem particularly consistent with contemporary forms of life, as well as with the principles and functioning mechanisms of the "participatory culture" (cf. Beer and Burrows 2010; Beer 2013) promoted by present-day digital mediascapes. They are interesting from the point of view of meaning-making processes, since they make veganism abandon the modal regime of rigid interdiction (havingnot-to-eat-meat) and powerlessness (not-being-able-to-eat-meat) in favour of permission (not-having-not-to-eat-meat) and liberty (being-able-to-eatmeat). Thus, the dualistic opposition between veganism and carnism fades

\footnotetext{
${ }^{8} 3.300$ people signed up to the first edition in 2014; by 2016, there were 23.000 participants, then 59.500 in 2017, 168.000 in 2018, 250.000 in 2019, and 400.000 in 2020.
} 
into a tensive relation, which seems to have more potential in describing the variety and complexity of present-day eating habits and trends.

\section{Digital irony and veganism}

There is another element that, albeit unmentioned in all marketing studies on veganism 2.0, seems crucial for its understanding: irony. Online communication is imbued with irony and a number of similar rhetoric strategies, such as parody, satire, sarcasm, mockery and hoaxes (Finocchi 2016). In this respect, the case of veganism is noteworthy. People have always laughed at vegetarians, and even more at vegans. As interestingly noted by Massimo Leone (2019), in fact, cultures generally laugh at what they consider their "accidents", that is to say, the uncontrollable ripples that arise in social semiosis and challenge their regular settings. Challenging the systems of values underlying common food practices and habits, veg(etari)anism is part of such "accidents". For this reason it has been the object of various forms of irony, which have found in online communication a powerful means to reach large audiences. Let us consider, for instance, the caricatural vegan chef "Germidi Soia" (literally, "Germs of Soy") performed by the Italian comic actor Maurizio Crozza. His videos, taken from the TV show "Crozza nel Paese delle Meraviglie", have reached millions of visualisations on YouTube and a number of shares on various social networks. Crozza's character makes fun of the vegan haute cuisine chef Simone Salvini, drawing on his dishes to laugh at foods and recipes which attempt to emulate non-vegan dishes (which is made clear by their designations, generally including prefixes such as "pseudo", "quasi", etc.) but in fact taste very different from them. They are also often flavourless or even disgusting (to the extent that the restaurant held by the caricatural chef is named Satut di Carton, meaning 'Everything tastes like Cardboard'). For this reason, he always ends up surrendering to meat, fish and other non-vegan options, confirming the common stereotype of the "tempted vegetarian" (cf. Rosewarne 2013; Martinelli 2015) and so the idea of a "natural" inclination to eat animal-derived food. Moreover, a hyperbolic representation of veganism is provided, with Germidi Soia psychoanalysing zucchini, cuddling peppers, talking to lettuce, etc. in order to prevent them from producing imaginary dangerous substances affecting their eaters' body. In this way he mocks the 
main claim of raw veganism, that is to say, the need to not process food products or alter them from their "natural" state9.

A number of memes (Fig. 3) and other messages circulating throughout Web 2.0 have reinforced such visions and valorisations, also exploiting other stereotyped figures, such as that of the "weak", not fully healthy vegan, who needs to artificially integrate (e.g. by means of supplements or enriched foods) nutritional elements into his/her diet, or that of the preachy, and even hostile, vegan, who has a sense of moral superiority and tries to convert everyone who is not vegan. Sexual and gender-related provocations have also been frequently used, reinforcing the attribution of machismo to the consumption of meat and other stereotypes associated with sexuality.
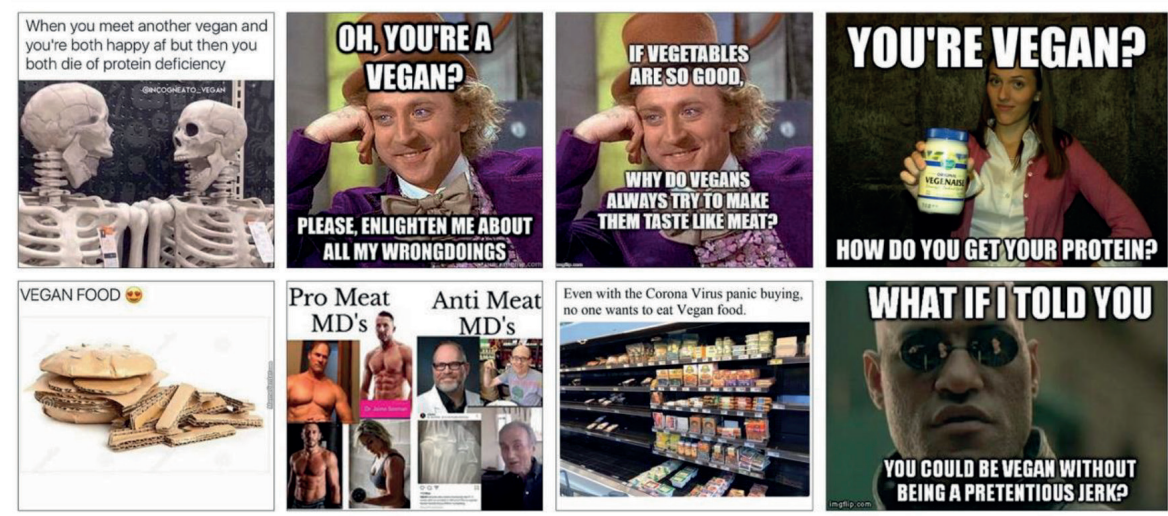

Fig. 3: Examples of Internet memes laughing at veganism.

On the other hand, it is very interesting to notice that ironic strategies have been also increasingly adopted in the promotion of veganism on social media, precisely by means of humoristic and satiric memes parodying and caricaturing anti-vegan claims and emphasising the positive aspects of veganism itself. The main thematic isotopies resulting from such messages, as illustrated by the examples shown in Fig. 4, can be described as follows:

- The criticism of the so-called "meat paradox" and especially of the mechanism of cognitive dissonance underlying it. How can people

\footnotetext{
${ }^{9}$ The reference therefore concerns a minor part of veganism, but interestingly highlights the idea of "nature", with which we will deal in the conclusion as regards to veganism 2.0. For more detailed observations on the widespread, yet highly problematic, use of such a concept in the more general field of food, see in particular Marrone 2011; 2015b; Stano $2015 ; 2017 ; 2018$.
} 
be concerned about animals (to the extent that, for instance, they cannot stand images of the animals burned in the recent Australian fires), but also eat them (enjoying seeing them while they "burn" on a grill)?

- The "unnaturality" of consuming animal-derived food, with messages emphasising the maternal connotation of milk feeding, and sarcastically referring to the "inability" of non-vegans to see it.

- The tastefulness of vegan food (to the extent that "non-vegans eat all the vegan food" at parties, or that they cannot imagine that they are actually eating vegan food, as they generally blame it for being flavourless or even disgusting), with an idea of (dis)taste interestingly referred not exclusively to the perceptual level, but also to the sociocultural and symbolic dimension (as the reference to offal remarks).
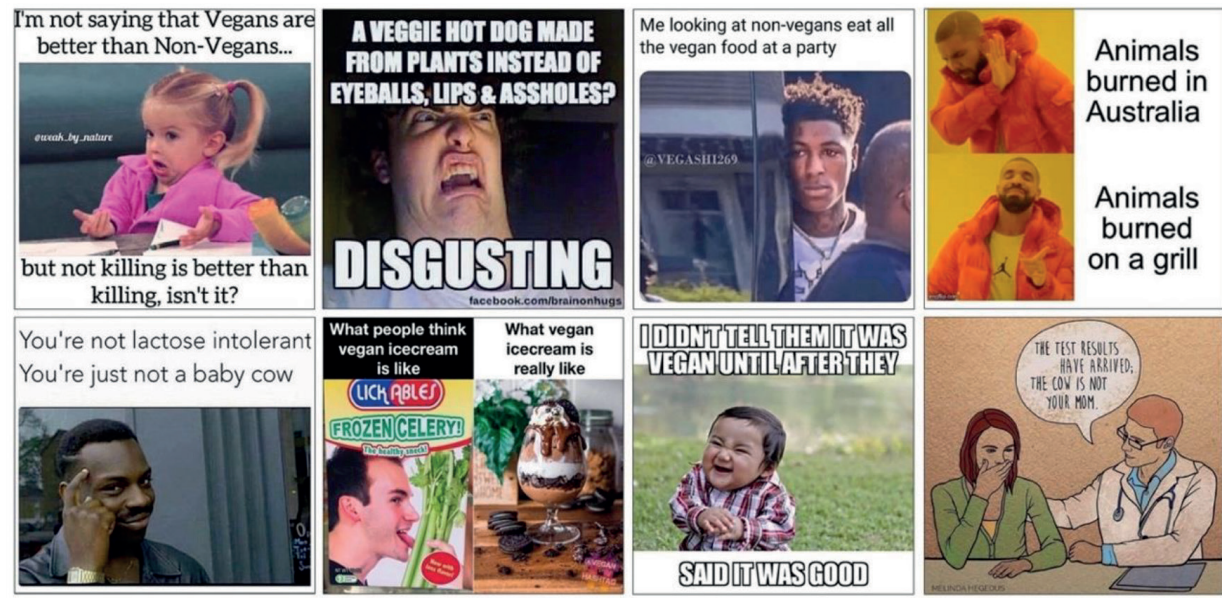

Fig. 4: Examples of Internet memes parodying anti-vegan claims.

In the exact same way as carnist memes, these messages operate a semantic inversion (antiphrasis), that is to say, a "reversal of perspective" (Russo Cardona 2009) which overturns the reference points of the interlocution, by originating a new sense of the involved situation and a subversion of the common point of view on veganism. These same mechanisms are at work also in more complex texts. Following the Covid-19 outbreak in Europe and the US, for instance, a post caught the attention of hundreds of people on Reddit, an American social news aggregation, web content rating, and discussion website that has a page specifically devoted to veganism (https:// www.reddit.com/r/vegan/) (Fig. 5). 


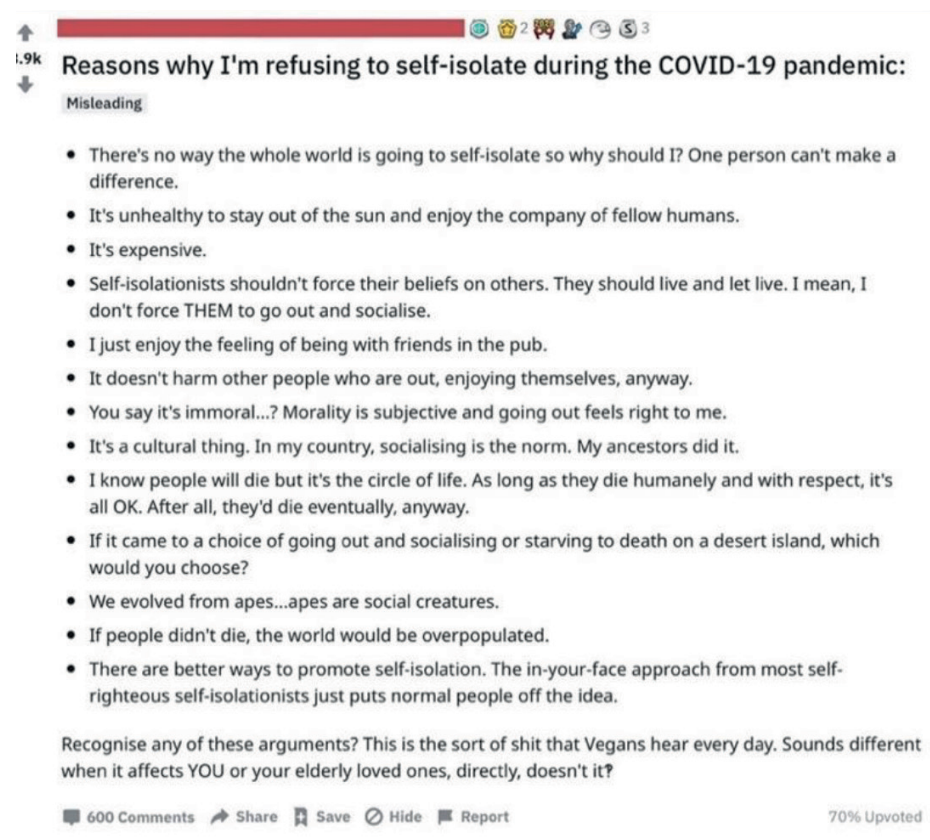

Fig. 5: A post on veganism adopting ironic strategies on Reddit ${ }^{10}$.

The arguments generally used against vegans (or, better, in favour of carnism) are in this case re-oriented toward a sphere of current public concern, which apparently goes against the measures adopted to safeguard other people, with a final revelation of the operated permutatio. Thus the message is able to "prick" its readers with a sarcastic movement provoking patemic reactions such as disdain and indignation at first, but also laughter (and eventually understanding and sympathy) at a later stage - as well reflected by the reader's comments.

\section{Conclusion: veganism, gastromaniac nutrition and digital com- munication}

Digital communication has opened up "new spaces to talk about food" (Rousseau 2012: x), leading to the creation of virtual communities based around it. Weblogs, discussion forums, and especially social media platforms provide opportunities to discuss and represent food and eating that are able to reach much larger audiences than older forms of media (Lupton 2018). Thus, as we have shown above, the collective identity of veganism

\footnotetext{
${ }^{10}$ Data has been minimised and anonymised in order to comply with ethics requirements.
} 
has acquired more and more strength, to become a dominant trend in the foodsphere.

From the point of view of communicative processes, we have highlighted the crucial role played in such a growth by the new paradigms that seem to regulate digital communication. Advances in technology have reduced the importance of the media in shaping their users' agenda, making it easier for people all around the world to exchange information and find other people with similar agendas and interact with them ${ }^{11}$. In this sense, the figure of the influencer has emerged as crucial, emphasising the importance of the patemic dimension and personal involvement as regards the ability to prick the reader and hence to increase his/her engagement. Although mainly neglected by marketing research, irony also seems to be a decisive factor in this respect, combining the capability to activate a passional programme with a cognitive function consisting of showing a new perspective, unveiling a new meaning, realising an unpredictable possibility. What is more - and particularly interesting in the case of veganism 2.0 (especially as regards its emulation of the strategies used in carnist humour) - , the practice of irony represents a means through which the "enunciator" (cf. Greimas \& Courtés 1979) manifests itself as an uttering entity, thus asserting his or her existence.

Contemporary gastromania and the related process of aestheticisation of food and taste have also proved fundamental in the spread and development of veganism 2.0. The new media have extraordinarily extended the boundaries of the iconographic representation of food, making the beau $a$ regarder (lit. 'good to look at') become the basis of the famous Lévi-Straussian principle bon à penser, bon à manger ('good to think, go to eat') ${ }^{12}$. Smartphones and cameras have become essential elements of table setting,

11 These new paradigms are generally referred to by means of the expression "agenda melding", intended as "the process by which audience members seek out and blend media agendas from various communication sources to fit their individual preferences and cognitions. Where the media can set the public agenda by influencing the salience of key issues, along with details or attributes about those issues, agenda melding argues that the already established values and attitudes of audience members play a role in the way in which such issues and attributes are sought out and mixed — or melded — into a coherent individual picture of events. Agenda setting focuses on the power of media to set agendas. Agenda melding concentrates on the ability of audience members to select among media, issues, and elements of messages. With agenda melding audiences are not passive but actively select messages from the plethora of those available" (Lee Kaid \& Holtz-Bacha 2008: 11-12; cf. Shaw, McCombs, Weaver \& Hamm 1999; Ragas \& Roberts 2009).

${ }^{12}$ In contrast with cultural materialism, Lévi-Strauss (1962) maintained that, in order to be "good to eat", substances should be first of all "good to think", that is to say, that our 
together with cutlery, glasses and other utensils, fomenting a "hypertrophy of vision" (Marrone 2014a) that has made of "food selfies" - i.e. "photos that people take of the food they have prepared or purchased ... and share on social media platforms before or while consuming it" (Lupton 2018; cf. Highfield \& Leaver 2016) - a powerful tool through which individuals, communities and also businesses convey messages about their identities and values. As discussed in detail above, a sort of universal code for the online representation of food has quickly imposed itself, giving origin to the so-called "food porn" phenomenon. Such a universal code has contributed to highlight the potential of vegan food in such an aesthetic and aestheticised domain - especially due to its vivid chromatic configurations and the possibility to easily cut and assemble it to form different shapes - , as well at to attenuate the differences among vegan and non-vegan food. This, as we have emphasised, reflects a modification at the level of food design and production. In recent years, the number of "faux burgers" and other vegan products that emulate not only the shape, but also the flavour of non-vegan products has increased exponentially, thus facilitating the transition between these gastrospheres. Actually, taste is precisely one of the aspects that are most frequently emphasised by vegans 2.0 (although marketing research tends to overlook this factor). Vegan food as represented in and by social media is not only healthy, ethical and environmentally sustainable, but also increasingly tasty (as remarked by the large amount of hashtags recalling this aspect, together with other visual and verbal content, also including ironic messages). This is very interesting, since it seems to mark an estrangement from the ideology of nutritionism that has been dominant in the last decades. In fact, in contemporary foodspheres, agro-food industrialization has eroded the socio-cultural constraints that used to regulate the gastronomic universe, thus allowing for more autonomy and freedom in food choices, but at the same time creating gastro-anomy ${ }^{13}$ and insecurity (Fischler 1979). Within this framework, the nutritional dimension has been increasingly adopted as a dominant "system of classification" of edible and inedible substances. This can be seen as an attempt to reintroduce a normative logic into everyday eating, even though in a reductionist man-

biological need for nourishment is always inserted in a system of values and meanings that reflect the society or culture we live in.

13 The expression is a blending of the French words gastronomie, 'gastronomy', and anomie, the idea of 'normlessness' popularised by Émile Durkheim (1897) to describe the condition of instability between the individual and society resulting from the breakdown of social standards and values. 
ner and on the basis of a process of de-contextualization, simplification and exaggeration of the role of nutrients:

Nutrition scientists, dieticians, and public health authorities - the nutrition industry, for short - have implicitly or explicitly encouraged us to think about foods in terms of their nutrient composition, to make the connection between particular nutrients and bodily health, and to construct "nutritionally balanced" diets on this basis. ... I refer to this nutritionally reductive approach to food as the ideology or paradigm of nutritionism. This focus on nutrients has come to dominate, to undermine, and to replace other ways of engaging with food and of contextualizing the relationship between food and the body (Scrinis 2008: 39).

Vegan food, at first excluded from the sphere of health on the basis of a common stereotype which identifies it as the cause of nutritional deficiencies, weakness and even disease - an image that still persists in some ironic messages circulating on the web, as we showed above - , has quickly become one of the crucial elements of this ideology. It has become so as part of the broader phenomenon of "clean eating" (McCartney 2016; Baker \& Walsh 2020), which reunites a series of widespread trends based on the refusal of processed foods (from GMOs to refined sugar or flours and animal-derived products) and the praise of "free from" (additives, preservatives, etc.) and "natural" (e.g. organic) products. On the other hand, advances in food production, but also and especially the convergence with the new forms of representation and communication of food online, have enlarged the gastronomic connotation of veganism, emphasising its ludic-aesthetic and utopian valorisation. This is noteworthy, since it goes beyond the simplistic approach of nutritionism and recovers a more complex and structured vision of food as a rich and varied set of physiologic, aesthetic, ethical, and also political elements. In fact, as we remarked above, plurality and variability also characterise the practices of consumption of vegan food 2.0. By extending the borders of "traditional veganism", based on interdiction and powerlessness, plant-based eating habits promoted by social media rather foster flexibility and openness, accentuating the continuous processes of translation taking place within the realm of food.

The result is a more varied and variable system, which does not strictly prohibit but rather regulate food choices. It does not impose interdictions but rather directs possibilities, exactly like dietetics (understood in its etymological sense, far from the reductionist vision prevailing in contemporary gastro-anomy and nutritionism) should do. It is a system able to 
recover the ethical and political dimension of gastronomy, while rejecting rigid prescriptions or obligations in favour of taste (intended, in its broader sense, as the ability to judge and recognise what is good or suitable), thus opening the way to the triumph over the lack of depth and concern brought about by the gastromania urged by Gianfranco Marrone (2019). Interestingly and somehow provocatively, the case of veganism 2.0 analysed in this paper shows us not only that such a triumph is possible, but also that it can pass precisely through the encounter with gastromania itself.

\section{Acknowledgment}

This project has received funding from the European Union's Horizon 2020 research and innovation programme under the Marie Sklodowska-Curie grant agreement No 795025. It reflects only the author's view and the Research Executive Agency is not responsible for any use that may be made of the information it contains.

\section{References}

Ashley, B., J. Hollows, S. Jones and B. Taylor. 2004. Food and Cultural Studies. London \& New York: Routledge.

Baker, S. A., M. J. Walsh. 2020. You Are What You Instagram: Clean Eating and the Symbolic Representation of Food. In Lupton, D., Z. Feldman. (eds.). Digital food cultures. London: Routledge, 53-60.

Bankov, K. 2021. "Face and Trust: A Semiotic Inquiry into Influencers, Money, and Amygdala”. Sign Systems Studies, Vol. 50 (in press).

Barthes, R. 1973. Le plaisir du texte. Paris: Éditions du Seuil.

Barthes, R. 1981 [1980]. Camera Lucida: Reflections on Photography. New York: Hill and Wang.

Beer, D. 2013. Popular Culture and New Media: The Politics of Circulation. Houndmills: Palgrave Macmillan.

Beer, D., R. Burrows. 2010. Consumption, Prosumption and Participatory Web Cultures: An Introduction. Journal of Consumer Culture, Vol. 10, Issue 1, $3-12$.

Coward, R. 1984. Female Desire. London: Paladin.

Durkheim, É. 1897. Le suicide: étude de sociologie. Paris: F. Alcan. 
Ferraro, G. 1998. Il mercato dei desideri. In Ferraro, G. (a cura). L'emporio dei segni. Rome: Meltemi, 9-40.

Finocchi, R. (ed.) 2015. Strategie dell'ironia nel web - Carte semiotiche. Annali 3. Lucca: VoLo Publisher.

Fischler, C. 1979. "Gastro-nomie et gastro-anomie”. Communications, Vol. 31, 189-210.

Floch, J.-M. 1990. Sémiotique, marketing et communication. Sous les signes, les strategies. Paris: Presses universitaires de France.

Freberga, K., K. Grahamb, K. McGaugheyc and L. A. Freberg. 2011. "Who Are the Social Media Influencers? A Study of Public Perceptions of Personality”. Public Relations Review, Vol. 37, Issue 1, 90-92.

Friedlander, J., C. Riedy. 2018. "Celebrities, Credibility, and Complementary Frames: Raising the Agenda of Sustainable and Other 'Inconvenient' Food Issues in Social Media Campaigning". Communication Research and Practice, Vol. 4, Issue 3, 229-245.

Greimas, A. J., J. Fontanille. 1991. Sémiotique des passions: Des états de choses aux états d'âme. Paris: Seuil.

Greimas, A. J., J. Courtés (eds.). 1979. Sémiotique. Dictionnaire raisonné de la théorie du langage. Paris: Hachette.

Highfield, T., T. Leaver. 2016. "Instagrammatics and Digital Methods: Studying Visual Social Media, from Selfies and GIFs to Memes and Emoji”. Communication Research and Practice, Vol. 2, Issue 1, 47-62.

Lee Kaid, L., C. Holtz-Bacha. 2008. "Agenda Melding”. Encyclopedia of Political Communication, 11-12. Thousand Oaks, California: SAGE Publications.

Leitzmann, C. 2014. "Vegetarian Nutrition. Past, Present, Future". American Journal of Clinical Nutrition, Vol. 100, 496S-502S.

Leone, M. 2019. Semiotica del cibo comico: sul senso dell'ilarità alimentare. In Politiche della cucina: Discorsi, conflitti, culture. E/C. Rivista dell'Associazione Italiana di Studi Semiotici, Anno XIII, n. 27. Available at: http://www. ec-aiss.it/archivio/tipologico/autore.php (accessed 5 April 2020).

Lévi-Strauss, C. 1962. Le totémisme aujourd'hui. Paris: Presses universitaires de France.

Lupton, D. 2018. Cooking, Eating, Uploading: Digital Food Cultures. In LeBesco, K., P. Naccarato (eds.). The Bloomsbury Handbook of Food and Popular Culture. London: Bloomsbury Academic, 66-79. 
Marrone, G. 2011. Addio alla Natura. Turin: Einaudi.

Marrone, G. 2014a. Buono da pensare. Rome: Carocci.

Marrone, G. 2014b. Gastromania. Milan: Bompiani.

Marrone, G. 2015a. "Food Porn”. Doppiozero. Available at: https://www.doppiozero.com/materiali/critica-del-gusto/food-porn (accessed 30 March 2020).

Marrone, G. 2015b. Semiotica del gusto. Linguaggi della cucina, del cibo, della tavola. Milan-Udine: Mimesis.

Marrone, G. 2019. Dopo la cena allo stesso modo. Dieci anni di immaginario gastronomico. Palermo: Torri del vento Edizioni.

Martinelli, D. 2015. The Naïve, the Eccentric and the Maniac: On the Filmic Representation of Vegetarians. In Lexia. Rivista di semiotica, 19-20, 283-297.

Martinelli, D., A. Berkmanienè. 2018. "The Politics and the Demographics of Veganism: Notes for a Critical Analysis". International Journal for the Semiotics of Law, Vol. 31, No. 3, 501-530.

McCartney, M. 2016. "Clean Eating and the Cult of Healthism". British Medical Journal, 354: 44095.

McCombs, M., A. Reynolds. 2002. News Influence on Our Pictures of the World. In Bryant, J., D. Zillmann (eds.). Media Effects: Advances in Theory and Research. 2nd ed. Mahwah, New Jersey: Lawrence Erlbaum Associates, $1-18$.

McDonnell, E. M. 2016. Food Porn: The Conspicuous Consumption of Food in the Age of Digital Reproduction. In Bradley, P. (ed.). Food, Media and Contemporary Culture: The Edible Image. Basingstoke, New York: Palgrave Macmillan, 239-265.

Ragas, M., M. Roberts. 2009. "Agenda Setting and Agenda Melding in an Age of Horizontal and Vertical Media: A New Theoretical Lens for Virtual Brand Communities". Journalism \& Mass Communication Quarterly, Vol. 86, Issue 1, 45-64.

Rosewarne, L. 2013. The Vegetarian Chapter: Introducing the Hippies, Sad Sacks, and Fundamentalists. In Id., American Taboo: The Forbidden Words, Unspoken Rules, and Secret Morality of Popular Culture. Santa Barbara, California: Praeger, 87-114.

Rousseau, S. 2012. Food and Social Media: You Are What You Tweet. Lanham, Maryland: Altamira Press/Rowman and Littlefield.

Russo Cardona, T. 2009. Le peripezie dell'ironia. Sullarte del rovesciamento del discorso. Rome: Meltemi. 
Schouten, A. P., L. Janssen, M. Verspaget. 2019. "Celebrity vs. Influencer Endorsements in Advertising: The Role of Identification, Credibility, and Product-Endorser Fit". International Journal of Advertising, Vol. 39, Issue 2, 258-281.

Scrinis, G. 2008. "On the Ideology of Nutritionism”. Gastronomica, Vol. 8, No. 1, 39-48.

Shaw, D. L., M. McCombs, D. H. Weaver, B. J. Hamm. 1999. "Individuals, Groups, and Agenda Melding: A Theory of Social Dissonance". International Journal of Public Opinion Research, Vol. 11, No. 1, 2-24.

Stano, S. 2015. Il crudo, il cotto e l'autentico: il cibo tra natura e naturalizzazione. In Ferraro, G., A. Giannitrapani, G. Marrone, S. Traini (a cura). Dire la natura. Ambiente e significazione. Rome: Aracne, 421-428.

Stano, S. 2017. "Lalimentazione tra natura e naturalismi: riflessioni semiotiche sulla dieta mediterranea”. CoSMo, Vol. 10, 33-50.

Stano, S. 2018. I sensi del cibo. Elementi di semiotica dellalimentazione. Rome: Aracne.

Stepaniak, J. 2000. The Vegan Sourcebook. New York: McGraw Hill Professional.

Tafesse, W., B. P. Wood. 2020. "Followers' Engagement with Instagram Influencers: The Role of Influencers' Content and Engagement Strategy”. Journal of Retailing and Consumer Services, Vol. 58, 1-9.

Vincent, L. 2002. Legendary Brands: Unleash the Power of Storytelling to Create a Winning Marketing Strategy. Chicago: Dearborn Trade Publishing. 